\title{
Boost Radiation Therapy
}

National Cancer Institute

\section{Source}

National Cancer Institute. Boost Radiation Therapy. NCI Thesaurus. Code C137908.

Supplemental radiation delivered to a specific area of interest, often to the tumor site itself. 